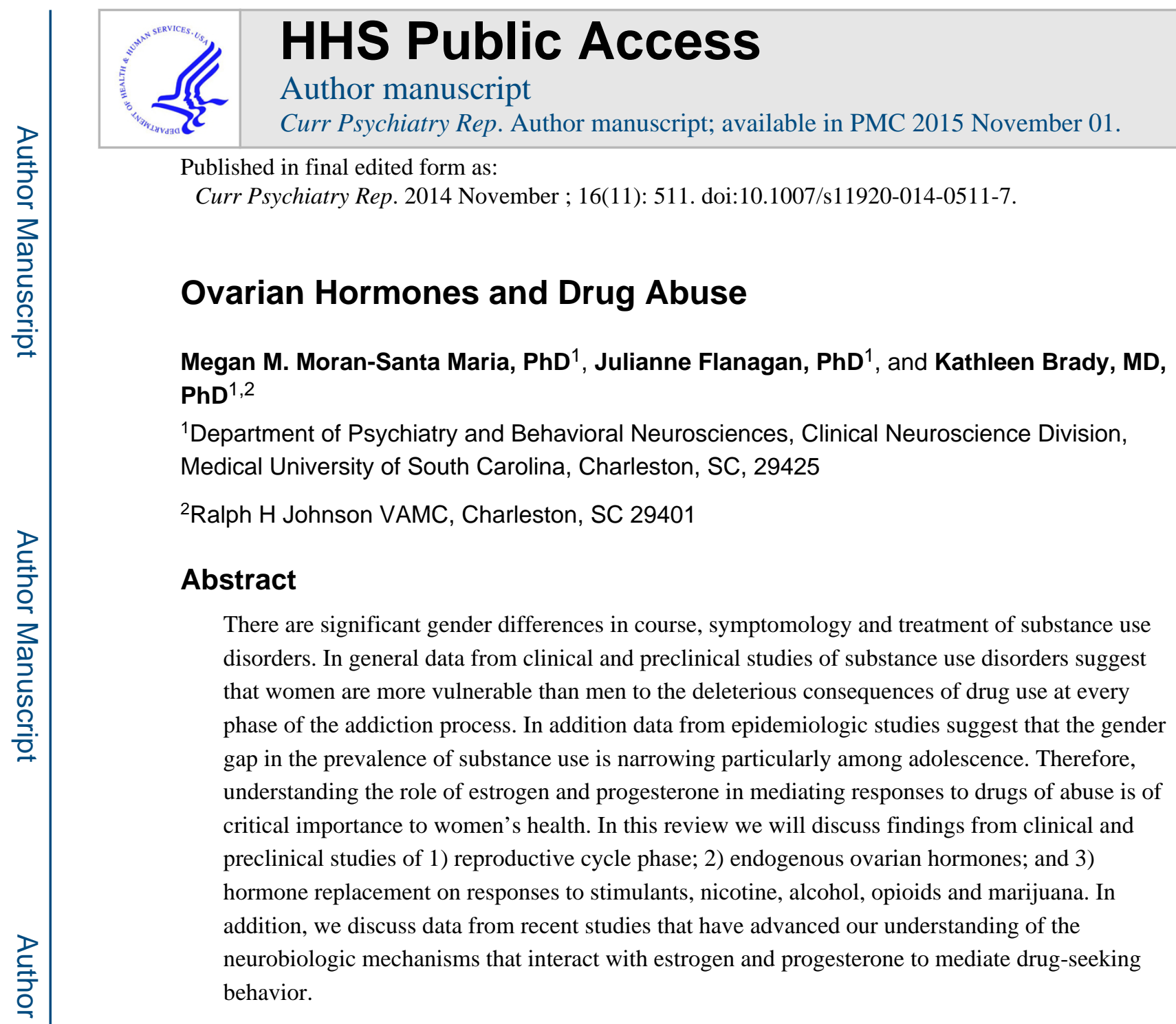

\title{
Introduction
}

For many years, research in the area of addictions, both preclinical and clinical, was focused on males only and gender differences were considered inconsequential. However, research conducted over the last two decades suggests important gender differences in every stage of the addiction process. For example, women initiate drug use at an earlier age, use more addictive routes of administration, meet criteria for substance use disorders faster and enter treatment programs earlier than men [1-5]. Findings from preclinical models of the transition phases (drug initiation, binging and relapse) are unequivocal. Compared with male rodents, female rodents acquire drug self-administration faster, exhibit greater binge like drug intake, are more resistant to drug extinction and exhibit greater drug-seeking behavior in response to triggers of relapse [6-11]. Thus, although the prevalence of addiction appears to be greater in men than in women, the effects of short and long-term drug use can be particularly damaging for women. These gender differences may be a result of psychosocial differences, biologic differences or a combination of factors. In this review we will present

Corresponding Author, Megan Moran-Santa Maria, Ph.D., MUSC, Department of Psychiatry and Behavioral Sciences, Clinical Neurosciences Division, 125 Doughty Street, Charleston, SC 29425, Phone: (843) 792-8187, Fax: (843) 792-4817, moranm@musc.edu. 
an overview of findings from clinical and preclinical studies of the impact of estrogen and progesterone on responses to stimulants, nicotine, opioids, marijuana and alcohol as well as recent studies investigating the neurobiologic mechanisms underlying the impact of ovarian hormones on drug effects and drug-related behavior.

\section{Female Reproductive Cycle}

The human female reproductive cycle typically lasts 28 days and is roughly divided into the follicular phase and the luteal phase. Menses occurs during the early follicular phase and marks a period of low and relatively stable levels of estrogen and progesterone. During the mid-follicular phase, estrogen levels begin to increase and peak just prior to ovulation while progesterone levels remain low. The luteal phase begins after ovulation. Progesterone levels begin to rise and peak 3-8 days after ovulation and decline prior to menses. In contrast to the human menstrual cycle, the rodent estrous cycle lasts four days. Most of the preclinical addictions research has focused on estrus and proestrus phases of the reproductive cycle since the estrus phase of the rat and early follicular phase in women are both characterized by relatively low levels of progesterone and estrogen. Progesterone and estrogen levels peak during proestrus, the rise in progesterone is a hallmark of the luteal phase in women [12]. Non-human primates have also been used to investigate the role of ovarian hormone levels and drug seeking behavior. Monkey reproductive cycles are similar to human cycles and afford the opportunity to measure daily hormone levels that can be difficult to collect in an out-patient clinic and in non-treatment seeking women with substance use disorders.

\section{Stimulants}

Research on ovarian hormone influences on responses to drugs of abuse has primarily focused on stimulants such as cocaine and methamphetamine. In general, clinical studies have found that the positive reinforcing effects (drug liking, euphoria and high) of cocaine and methamphetamine are greater during the follicular phase than during the luteal phase [13-16]. These data are consistent with preclinical data that suggest that the presence of progesterone during the luteal phase attenuates the reinforcing effects of stimulants or that the presence of estrogen in the follicular phase enhances the reinforcing effects of stimulants [17-20]. However, other clinical studies have failed to demonstrate an effect of menstrual cycle phase on subjective responses to intranasal or intravenous cocaine administration [2123]. These disparate findings may reflect differences in the route of drug administration (i.e. smoked cocaine vs. intranasal or intravenous cocaine administration) or differences in the methodology for tracking menstrual cycle-related hormonal changes. As noted above, significant fluctuations in ovarian hormones occur within each phase of the menstrual cycle. As such, direct measures of endogenous estrogen and progesterone levels may be the more accurate methodology for investigating the impact of ovarian hormones on the behavioral responses to stimulants and mood in stimulant-dependent women. In one study, Sinha and colleagues found that cocaine-dependent women with high levels of endogenous progesterone (> $4 \mathrm{ng} / \mathrm{ml}$ ) reported significantly lower cue- and stress-induced craving as compared to women with low levels of endogenous progesterone [24]. Another study compared endogenous estrogen and progesterone levels between recently abstinent cocainedependent women and a group of healthy control women. Salivary estrogen and 
progesterone levels were collected daily for 28-days. Compared to the control group, cocaine-dependent women exhibited significantly greater levels of salivary progesterone and lower estrogen to progesterone ratios throughout the menstrual cycle [25]. These findings suggest that while cycle duration and ovulation remain intact in cocaine-dependent women [13], chronic cocaine use and/or abstinence may alter the hormonal milieu. Cocaine craving was associated with the estrogen to progesterone ratio during the late luteal phase [25], suggesting that reductions in progesterone that occur during the late luteal phase may make this a period of high risk for drug craving and relapse for women.

A growing literature demonstrates that exogenous progesterone administration attenuates the positive subjective responses to smoked and intravenous cocaine in cocaine-dependent women [26-28]. Thus, increasing progesterone may protect against the reinforcing effects of stimulants and attenuate risk for drug-primed craving and relapse. Drug-paired cues and stress are also significant predictors of craving and relapse. Fox and colleagues (2013) examined the impact of exogenous progesterone on subjective and endocrine responses to guided imagery of imagery of stress, drug-cues and relaxing conditions in early abstinent cocaine-dependent men and women. Subjects received daily doses of micronized progesterone (400 mg/day) or placebo for seven days. Compared to placebo, progesterone significantly attenuated cue-induced craving and cortisol levels, but increased cue-induced corticotropin levels. Progesterone also improved cognitive performance in both men and women. Women receiving progesterone reported lower ratings of negative mood and higher ratings of relaxed mood in response to the stress condition. Interestingly, this finding was not observed in men [29]. Similarly, a clinical trial found that cocaine-dependent men treated with progesterone had a lower probability of having a negative urine drug screen than cocaine-dependent men treated with placebo [30]. These data are consistent with findings from a preclinical study suggesting that the progesterone metabolite allopregnanolone attenuated methamphetamine-induced reinstatement in female rodents but not in male rodents [31]. Thus, in stimulant dependence, the effects of exogenous progesterone/allopregnanolone administration on drug seeking behavior may be moderated by both sex and the context of the cue.

As noted above preclinical studies have consistently found that estrogen enhances the reinforcing effects of stimulants [7, 18, 19]. Ramoa and colleagues used an extended access self-administration model of "binge-like" drug seeking behavior to examine the role of estrogen in the vulnerability of females to the addicted phenotype. Following two weeks of abstinence from self-administration, ovariectomized (OVX) female rodents treated with estrogen (OVX-E) exhibited significantly greater cocaine-seeking behavior as compared to OVX rodents treated with vehicle (OVX-VEH) [32]. These results suggest that estrogen plays an important role for females in the transition from recreational drug use to compulsive drug seeking behavior. In a follow-up study, the same group examined the role of dopamine in mediating estrogen's effects on compulsive cocaine-seeking behavior. The dopamine D1 receptor antagonist SCH23390 was administered directly into the ventral striatum of OVX-E, OVX-VEH and intact female rodents. The D1 antagonist played a greater role in attenuating cocaine seeking behavior in OVX-VEH rodents compared to OVX-E and intact female rodents, suggesting that the facilitatory effects of estrogen on compulsive drug seeking behavior may be independent of D1 receptor activation [33]. These 
data are consistent with the extant literature suggesting that while dopamine is critical for the acute reinforcing effects of stimulants, glutamate plasticity in the striatum and prefrontal cortex plays a preeminent role in the addicted phenotype [34]. The estrogen receptor a is functionally coupled to metabotropic glutamate receptors (mGluRs) in the striatum [35, 36]. Martinez and colleagues explored the role of mGluRs as mechanism responsible for estrogen's enhancing effects on behavioral sensitization to cocaine. Administration of the mGluR5 receptor antagonist MPEP prevented the facilitatory effects of estrogen on cocaineinduced sensitization without impacting the acute responses to cocaine [37]. Thus, interactions between estrogen and the glutamate system may play a role in the maintaining the addicted phenotype.

\section{Nicotine}

Findings from clinical studies of nicotine-dependent women suggest that ovarian hormones affect symptoms of nicotine withdrawal and responses to triggers of smoking behavior. For example, urges to smoke and symptoms of nicotine withdrawal are elevated during the late luteal phase when progesterone levels begin to fall [38-40]. Female smokers exhibit greater craving to smoking cues during the luteal phase as compare to the follicular phase [40]. Other studies have found no effect of menstrual cycle phase on cognitive performance or subjective responses to nicotine administration in abstinent female smokers [41, 42]. A recent clinical laboratory study examined the effects of changes in endogenous levels of estrogen and progesterone on smoking behavior in nicotine-dependent women and found that decreases in estrogen and progesterone were associated with an increase in cigarette puff intensity [43]. Interestingly, the ratio of progesterone to estrogen was inversely associated with a greater number of puffs and weight of cigarettes smoked. In addition, this study found that the ratio of progesterone to estrogen and changes in estrogen and progesterone were the best predictors of smoking behavior. These data parallel findings in both preclinical and clinical studies demonstrating diminished attentiveness to nicotine following progesterone administration in the framework of low levels of estrogen (Lynch, 2009; Sofuoglu \& Mooney, 2009) and a reduction in relapse rates among female smokers who quit during the luteal phase compared to the follicular phase (Allen, et al., 2008). Importantly, these data suggest that reproductive phase and/or absolute levels of estrogen or progesterone may not be sufficient to explain the impact of ovarian hormones on nicotine seeking behavior and emphasize the importance of changing hormone levels and the estrogen/progesterone ratio. Including measurements of endogenous estrogen and progesterone over time may be particularly important for studies of ovarian hormones and smoking behavior in women.

Another clinical study investigated the dose-dependent effects of exogenous progesterone on smoking behavior and cognition in abstinent nicotine-dependent smokers. Participants received either 200 or $400 \mathrm{mg} /$ day of progesterone or placebo for three days. Interestingly the $400 \mathrm{mg}$ dose of progesterone attenuated the "urge" to smoke in both males and females [44]. In addition, males and females receiving the $200 \mathrm{mg}$ dose of progesterone improved their performance in the Digital Symbol Substitution Test. Females, but not males, showed improvements in the Stroop task. This is of importance because women have been demonstrated in several studies to be less responsive to pharmacotherapy for smoking 
cessation as compared to men [45-47]. As such, the finding that progesterone might be preferentially efficacious in smoking cessation for female smokers could have important clinical implications.

The $\beta 2$ subunit of the nicotinic acetylcholine receptor (nAChR) plays an important role in the primary reinforcing effects of nicotine and cigarette smoking up-regulates $\beta 2-\mathrm{nAChR}$ expression in the brain [48-51]. Of note, progesterone blocks nAChR function [52, 53]. Thus, the protective effects of progesterone on craving in nicotine-dependent women may be mediated through its inhibitory effect on $\beta 2$-nAChR function. A recent neuroimaging study used single photon emission computed tomography (SPECT) to measure the association between endogenous levels of ovarian hormones, $\beta 2$-nAChR availability and symptoms of nicotine withdrawal in recently abstinent nicotine-dependent cigarette smokers. In both smokers and non-smokers, $\beta 2$-nAChR availability was negatively correlated with progesterone levels but not with estrogen levels or with the ratio of estrogen to progesterone [54]. Higher progesterone levels were associated with greater self-reported depression, nicotine withdrawal and craving to smoke to relieve withdrawal. There was no association between $\beta 2$-nAChR availability and craving or symptoms of nicotine withdrawal. These findings suggest that the relationship between progesterone, craving and symptoms of nicotine withdrawal may be independent of $\beta 2-\mathrm{nAChR}$ receptor availability. It is important to note that the study included women on birth control and menopausal women which could impact endogenous hormone levels. Future studies examining interactions between ovarian hormones and 32 -nAChR in a more homogeneous group of women who are free of hormonal contraceptives may be warranted. In addition, given the findings of Schiller and colleagues [43], associations between changes in hormone levels and/or the progesterone to estrogen ratio in $\beta 2$-nAChR availability may also be of interest in future studies.

\section{Alcohol}

Studies of menstrual cycle phase effects on subjective response to alcohol have had conflicting results. One study of healthy non-dependent women found anxiogenic effects of alcohol during the luteal phase, but no effects of alcohol on anxiety during the follicular phase [55]. Others have found anxiogenic effects of alcohol during the follicular phase but not during the luteal phase [56]. These discrepant results may reflect differences in the doses of alcohol administered. Results from studies of menstrual cycle phase on the reinforcing effects of alcohol are also conflicting. Alcohol produced a greater increase in positive subjective during the luteal phase than during the follicular phase [57]. Another study compared responses to alcohol and alcohol intake in healthy women at four stages of the menstrual cycle; early follicular, late follicular, mid luteal and late luteal phases. The subjective effects of alcohol and volume of alcohol consumed did not vary across the menstrual cycle [58]. It is important to note that these data were collected from a group of healthy women without a history of alcohol use disorders. Individual variability in alcohol use may be an important determinant of menstrual cycle phase effects on alcohol intake. For example, binge drinking is prevalent in women who are at risk for eating disorders, and women who show patterns of restrictive eating consume greater amounts of alcohol [59-61]. A recent study examined the relationship between patterns of alcohol intake and dietary restraint as a function of menstrual cycle phase in a group of women who were at-risk for 
developing alcohol use disorders. Restrained eaters drank less than the unrestrained eaters during the follicular phase [62]. Menstrual cycle phase may also differentially affect alcohol consumption in women who restrict their eating. In addition, menstrual cycle phase may differentially affect responses to alcohol in women with a family history of alcoholism as compared to women without a family history of alcoholism [57]. Specifically, alcoholinduced dysphoria during the luteal phase is greater in women with a family history of alcohol use disorders than in women without a family history of alcohol use disorders.

Preclinical studies demonstrate significant effects of endogenous hormone levels and cycle phase on alcohol intake and behavior. For example, the rewarding effects of alcohol are found in intact female rats but not in OVX female rats [63]. Female rodents consume less alcohol during proestrus and estrus phases of the estrous cycle than they do during diestrus and metestrus [64]. In contrast to the findings of estrous cycle phase effects on aversive effects of cocaine, there appears to be no effect of estrous cycle phase on the conditioned aversive responses to alcohol in female rats $[63,65]$. Thus, estrous cycle phase effects on the motivation to use alcohol may be associated to a greater extent with the reinforcing effects of alcohol than attenuating the aversive effects of alcohol.

\section{Opioids}

Non-medical use of prescription opioids has increased substantially in the last 25 years and poses a significant clinical challenge to effective pain management [66]. Recent epidemiologic data indicate that women are more likely than men to experience chronic pain and the prevalence of prescription opioid misuse is increasing among women [67-69]. In addition, compared to opioid-dependent men, opioid-dependent women report greater craving, social impairment, medical and psychiatric dysfunction [70]. Despite these data few if any studies have examine ovarian hormone effects on opioid craving and drug-seeking behavior in women. Clinical studies have typically focused on the impact of menstrual cycle phase on the antinociceptive effects of opioids. One study found that the antinociceptive effects of fentanyl following laparoscopic surgery did not vary across the menstrual cycle [71]. A clinical laboratory study examined menstrual cycle phase effects on the magnitude of morphine or pentazocine analgesia in healthy women and in women taking oral contraceptives. Normally cycling women exhibited greater morphine analgesia for pain during the follicular phase than they did during the luteal phase of the menstrual cycle [72]. They found no effects of menstrual cycle phase on morphine analgesia in women taking oral contraceptives. In addition, there was no effect of menstrual cycle phase on responses to pentazocine in normally cycling women or in women taking oral contraceptives. Taken together these clinical data suggest that antinociceptive effects of opioids may be dependent upon the opioid and ovarian hormone status. Of note, clinical studies have collected hormone levels to confirm menstrual cycle phase, however direct measures of associations between estrogen and/or progesterone levels and responses to opioids have not been assessed. This could also explain the disparate findings among the existing clinical studies. Given the findings from clinical studies of endogenous ovarian hormone levels on responses to nicotine and stimulants [24, 43], future clinical studies exploring associations between ovarian hormones and responses to opioids are warranted. 
Preclinical studies have examined the effects of ovarian hormones on the reinforcing properties of opioids. One study found no effect of estrous cycle phase on the acquisition of heroin or morphine self-administration in intact female rodents [73]. Findings from other studies of opioid reinforcement in OVX female rats are conflicting. For example one study found no difference in the acquisition of heroin self-administration between OVX-VEH, OVX-E and OVX rodents treated with progesterone [74]. However another study found that OVX-E rodents acquired heroin self-administration faster than OVX-VEH rodents, suggesting that estrogen may enhance the reinforcing effects of heroin [75]. These disparate findings may be related to differences in doses, as Roth and colleagues suggested that smaller doses of heroin may have improved their ability to detect group differences in the reinforcing effects of heroin. Studies of progesterone on self-administration of smaller doses of heroin may provide additional insight into the role of ovarian hormones and opioid addiction. In addition, future studies examining estrogen and progesterone replacement $o$ relapse in OVX rodents with a history of opioid self-administration may also be warranted.

\section{Marijuana}

There have been few clinical studies of the impact of ovarian hormones on marijuana use and behavior. Several studies of marijuana users have found no effect of menstrual cycle phase on either marijuana or alcohol use [76, 77]. In addition, there appears to be little effect of menstrual cycle phase on negative affect, arousal, mood and concentration in marijuana users [77, 78]. Given the increase in marijuana use in women over the past few decades, clearly more clinical studies of ovarian hormones on craving and drug withdrawal are warranted.

Unlike the lack of findings from clinical studies, preclinical studies report significant modulatory effects of ovarian hormones on responses to cannabinoid administration. For example, OVX female rodents exhibit attenuated cue- and drug-induced cannabinoid seeking behavior as compared to intact female rodents [79]. Preclinical data also suggest that ovarian hormones can impact the long-term effects of marijuana on cognitive performance. Specifically, one study compared measures of cognitive performance between groups of adult intact female rats and adult OVX rats that had received $\Delta^{9}$-THC during adolescence. The intact group of female rodents had lower response rates on measures of learning and performance as compared to OVX rodents [80]. The same study found significant changes in CB-1 receptor expression in the striatum and hippocampus that were dependent upon the presence of ovarian hormones. The presence of ovarian hormones also impacted the response to $\Delta^{9}$-THC as adults. These data are particularly interesting as $\Delta^{9}$ THC increases pregnenolone levels in the brain through the CB-1 receptor. A recent study found pregnenolone attenuated the intoxicating effects of $\Delta^{9}$-THC suggesting that pregnenolone is an important component of a negative feedback system that attenuates rewarding effects of $\Delta^{9}$-THC [81]. Thus, exposure to $\Delta^{9}$-THC during adolescence may alter the sensitivity of CB-1 receptors to pregnenolone and thus play a role in cognitive deficits during adulthood $[80,82,83]$.

Curr Psychiatry Rep. Author manuscript; available in PMC 2015 November 01. 


\section{Conclusions and Future Directions}

The goal of this review was to provide an overview of the effects of ovarian hormones on responses to drugs of abuse. The most consistent effects of estrogen and progesterone appear to be found in response to stimulant administration, with estrogen enhancing and progesterone attenuating positive subjective responses to cocaine and amphetamine. Moreover, high endogenous progesterone levels appear to attenuate responses to stress and drug-paired cues in cocaine-dependent women. Findings from studies of nicotine dependence support progesterone's protective effects on drug seeking behavior. Cosgrove and colleagues' data suggests that these effects may be independent of $\beta 2-\mathrm{nAChR}$ receptors. The important work by Schiller and colleagues suggests that changes in ovarian hormone levels over time and/or the ratio of progesterone to estrogen may be better predictors of responses to drugs of abuse than absolute levels of estrogen or progesterone. Clinical data also support exogenous progesterone as an effective therapeutic for substance-dependent women. However, it is important to note that while most preclinical and clinical laboratory studies have found that progesterone attenuates the reinforcing effects of drugs, few if any studies have found that progesterone attenuates drug-self administration. Importantly, the gender gap in illicit drug use among adults and adolescents is narrowing [67]. To date, a significant knowledge gap remains in our understanding of the role of ovarian hormones in mediating drug-seeking behavior in marijuana-, alcohol- and opioid-dependent women. Adolescence is a critical period of structural and functional brain development, particularly within the executive control, reward and salience networks. More systematic investigation of ovarian hormones and drug reinforcement among adolescents are warranted. In addition, advances in human neuroimaging continue to provide critical insight into mechanisms that may underlie sex differences in the subjective effects of drugs and abuse as well as sex differences in pharmacotherapy. Neuroimaging studies with large sample sizes comparing adolescent, adult freely cycling and post-menopausal women to controls and in response to exogenous hormone administration across the menstrual cycle could advance our understanding of the mechanistic link between ovarian hormones and addiction. Moreover studies of glutamate and other important neurotransmitter/neuromodulators may be important for assessing the impact of ovarian hormones on drug withdrawal, relapse and craving in substance-dependent women.

\section{References}

1. McCance-Katz EF, Carroll KM, Rounsaville BJ. Gender differences in treatment-seeking cocaine abusers--implications for treatment and prognosis. Am J Addict. 1999; 8(4):300-311. [PubMed: 10598213]

2. Anglin MD, Hser YI, McGlothlin WH. Sex differences in addict careers. 2. Becoming addicted. Am J Drug Alcohol Abuse. 1987; 13(1-2):59-71. [PubMed: 3687885]

3. Hernandez-Avila CA, Rounsaville BJ, Kranzler HR. Opioid-, cannabis- and alcohol-dependent women show more rapid progression to substance abuse treatment. Drug Alcohol Depend. 2004; 74(3):265-272. [PubMed: 15194204]

4. Westermeyer J, Boedicker AE. Course, severity, and treatment of substance abuse among women versus men. Am J Drug Alcohol Abuse. 2000; 26(4):523-535. [PubMed: 11097190]

5. Brady KT, et al. Gender differences in substance use disorders. Am J Psychiatry. 1993; 150(11): 1707-1711. [PubMed: 8214180] 
6. Lynch WJ, Carroll ME. Reinstatement of cocaine self-administration in rats: sex differences. Psychopharmacology (Berl). 2000; 148(2):196-200. [PubMed: 10663435]

7. Lynch W. Acquisition and maintenance of cocaine self-administration in adolescent rats: effects of sex and gonadal hormones. Psychopharmacology (Berl). 2008; 197(2):237-246. [PubMed: 18066534]

8. Roth ME, Carroll ME. Sex differences in the escalation of intravenous cocaine intake following long- or short-access to cocaine self-administration. Pharmacol Biochem Behav. 2004; 78(2):199207. [PubMed: 15219759]

9. Kerstetter KA, et al. Protracted time-dependent increases in cocaine-seeking behavior during cocaine withdrawal in female relative to male rats. Psychopharmacology (Berl). 2008; 198(1):6375. [PubMed: 18265959]

10. Anker JJ, Carroll ME. Sex differences in the effects of allopregnanolone on yohimbine-induced reinstatement of cocaine seeking in rats. Drug Alcohol Depend. 2010; 107(2-3):264-267. [PubMed: 20005642]

11. Buffalari DM, et al. Corticotrophin releasing factor (CRF) induced reinstatement of cocaine seeking in male and female rats. Physiol Behav. 2012; 105(2):209-214. [PubMed: 21889522]

12. Freeman, M. The neuroendocrine control of the ovarian cycle of the rat. In: Knobil, E.; Neill, JD., editors. The physiology of reproduction. New York, NY: Raven Press; 1994. p. 613-658.

13. Evans SM, Haney M, Foltin RW. The effects of smoked cocaine during the follicular and luteal phases of the menstrual cycle in women. Psychopharmacology (Berl). 2002; 159(4):397-406. [PubMed: 11823892]

14. Sofuoglu M, et al. Sex and menstrual cycle differences in the subjective effects from smoked cocaine in humans. Exp Clin Psychopharmacol. 1999; 7(3):274-283. [PubMed: 10472516]

15. Justice AJ, de Wit $\mathrm{H}$, et al. Acute effects of d-amphetamine during the follicular and luteal phases of the menstrual cycle in women. Psychopharmacology (Berl). 1999; 145(1):67-75. [PubMed: 10445374]

16. White TL, Justice AJ, de Wit H, et al. Differential subjective effects of D-amphetamine by gender, hormone levels and menstrual cycle phase. Pharmacol Biochem Behav. 2002; 73(4):729-741. [PubMed: 12213517]

17. Feltenstein MW, See RE. Plasma progesterone levels and cocaine-seeking in freely cycling female rats across the estrous cycle. Drug Alcohol Depend. 2007; 89(2-3):183-189. [PubMed: 17240083]

18. Lynch WJ, et al. Role of estrogen in the acquisition of intravenously self-administered cocaine in female rats. Pharmacol Biochem Behav. 2001; 68(4):641-646. [PubMed: 11526960]

19. Chen $\mathrm{HH}$, et al. Methamphetamine-induced conditioned place preference is facilitated by estradiol pretreatment in female mice. Chin J Physiol. 2003; 46(4):169-174. [PubMed: 15074837]

20. Kippin TE, et al. Potentiation of cocaine-primed reinstatement of drug seeking in female rats during estrus. Psychopharmacology (Berl). 2005; 182(2):245-252. [PubMed: 16001116]

21. Lukas SE, et al. Sex differences in plasma cocaine levels and subjective effects after acute cocaine administration in human volunteers. Psychopharmacology (Berl). 1996; 125(4):346-354. [PubMed: 8826539]

22. Collins SL, et al. Intranasal cocaine in humans: effects of sex and menstrual cycle. Pharmacol Biochem Behav. 2007; 86(1):117-124. [PubMed: 17257663]

23. Mendelson JH, et al. Cocaine pharmacokinetics in men and in women during the follicular and luteal phases of the menstrual cycle. Neuropsychopharmacology. 1999; 21(2):294-303. [PubMed: 10432477]

24. Sinha R, et al. Sex steroid hormones, stress response, and drug craving in cocaine-dependent women: implications for relapse susceptibility. Exp Clin Psychopharmacol. 2007; 15(5):445-452. [PubMed: 17924778]

25. Fox HC, et al. Altered levels of sex and stress steroid hormones assessed daily over a 28-day cycle in early abstinent cocaine-dependent females. Psychopharmacology (Berl). 2008; 195(4):527-536. [PubMed: 17891383]

26. Evans SM, Foltin RW. Exogenous progesterone attenuates the subjective effects of smoked cocaine in women, but not in men. Neuropsychopharmacology. 2006; 31(3):659-674. [PubMed: 16160708] 
27. Sofuoglu M, Babb DA, Hatsukami DK. Effects of progesterone treatment on smoked cocaine response in women. Pharmacol Biochem Behav. 2002; 72(1-2):431-435. [PubMed: 11900816]

28. Sofuoglu M, Mitchell E, Kosten TR. Effects of progesterone treatment on cocaine responses in male and female cocaine users. Pharmacol Biochem Behav. 2004; 78(4):699-705. [PubMed: 15301924]

29. Fox HC, et al. The effects of exogenous progesterone on drug craving and stress arousal in cocaine dependence: impact of gender and cue type. Psychoneuroendocrinology. 2013; 38(9):1532-1544. [PubMed: 23374328]

30. Sofuoglu M, et al. Progesterone effects on cocaine use in male cocaine users maintained on methadone: a randomized, double-blind, pilot study. Exp Clin Psychopharmacol. 2007; 15(5):453460. [PubMed: 17924779]

31. Holtz NA, et al. Reinstatement of methamphetamine seeking in male and female rats treated with modafinil and allopregnanolone. Drug Alcohol Depend. 2012; 120(1-3):233-237. [PubMed: 21820819]

32. Ramoa CP, et al. Estradiol as a mechanism for sex differences in the development of an addicted phenotype following extended access cocaine self-administration. Neuropsychopharmacology. 2013; 38(9):1698-1705. [PubMed: 23481437]

33. Ramoa CP, et al. Diminished role of dopamine D1-receptor signaling with the development of an addicted phenotype in rats. Biol Psychiatry. 2014; 76(1):8-14. [PubMed: 24199666]

34. Kalivas PW, Volkow ND. The neural basis of addiction: a pathology of motivation and choice. Am J Psychiatry. 2005; 162(8):1403-1413. [PubMed: 16055761]

35. Meitzen J, Mermelstein PG. Estrogen receptors stimulate brain region specific metabotropic glutamate receptors to rapidly initiate signal transduction pathways. J Chem Neuroanat. 2011; 42(4):236-241. [PubMed: 21458561]

36. Peterson BM, Mermelstein PG, Meisel RL. Estradiol mediates dendritic spine plasticity in the nucleus accumbens core through activation of mGluR5. Brain Struct Funct. 2014

37. Martinez LA, et al. Estradiol facilitation of cocaine-induced locomotor sensitization in female rats requires activation of mGluR5. Behav Brain Res. 2014; 271:39-42. [PubMed: 24893316]

38. Allen SS, et al. Withdrawal and pre-menstrual symptomatology during the menstrual cycle in short-term smoking abstinence: effects of menstrual cycle on smoking abstinence. Nicotine Tob Res. 1999; 1(2):129-142. [PubMed: 11072394]

39. Allen SS, et al. Effects of transdermal nicotine on craving, withdrawal and premenstrual symptomatology in short-term smoking abstinence during different phases of the menstrual cycle. Nicotine Tob Res. 2000; 2(3):231-241. [PubMed: 11082823]

40. Franklin TR, et al. Retrospective study: influence of menstrual cycle on cue-induced cigarette craving. Nicotine Tob Res. 2004; 6(1):171-175. [PubMed: 14982700]

41. Marks JL, Pomerleau CS, Pomerleau OF. Effects of menstrual phase on reactivity to nicotine. Addict Behav. 1999; 24(1):127-134. [PubMed: 10189980]

42. Pomerleau CS, et al. Effects of nicotine abstinence and menstrual phase on task performance. Addict Behav. 1994; 19(4):357-362. [PubMed: 7992670]

43. Schiller CE, et al. Association between ovarian hormones and smoking behavior in women. Exp Clin Psychopharmacol. 2012; 20(4):251-257. [PubMed: 22545725]

44. Sofuoglu M, Mouratidis M, Mooney M. Progesterone improves cognitive performance and attenuates smoking urges in abstinent smokers. Psychoneuroendocrinology. 2011; 36(1):123-132. [PubMed: 20675057]

45. Cepeda-Benito A, Reynoso JT, Erath S. Meta-analysis of the efficacy of nicotine replacement therapy for smoking cessation: differences between men and women. J Consult Clin Psychol. 2004; 72(4):712-722. [PubMed: 15301656]

46. Perkins K. Smoking cessation in women. Special considerations. CNS Drugs. 2001; 15(5):391411. [PubMed: 11475944]

47. Scharf D, Shiffman S. Are there gender differences in smoking cessation, with and without bupropion? Pooled- and meta-analyses of clinical trials of Bupropion SR. Addiction. 2004; 99(11): 1462-1469. [PubMed: 15500599] 
48. King SL, Caldarone BJ, Picciotto MR. Beta2-subunit-containing nicotinic acetylcholine receptors are critical for dopamine-dependent locomotor activation following repeated nicotine administration. Neuropharmacology. 2004; 47(Suppl 1):132-139. [PubMed: 15464132]

49. Picciotto MR, et al. Acetylcholine receptors containing the beta2 subunit are involved in the reinforcing properties of nicotine. Nature. 1998; 391(6663):173-177. [PubMed: 9428762]

50. Staley JK, et al. Human tobacco smokers in early abstinence have higher levels of beta2* nicotinic acetylcholine receptors than nonsmokers. J Neurosci. 2006; 26(34):8707-8714. [PubMed: 16928859]

51. Cosgrove KP, et al. beta2-Nicotinic acetylcholine receptor availability during acute and prolonged abstinence from tobacco smoking. Arch Gen Psychiatry. 2009; 66(6):666-676. [PubMed: 19487632]

52. Ke L, Lukas RJ. Effects of steroid exposure on ligand binding and functional activities of diverse nicotinic acetylcholine receptor subtypes. J Neurochem. 1996; 67(3):1100-1112. [PubMed: 8752117]

53. Valera S, Ballivet M, Bertrand D. Progesterone modulates a neuronal nicotinic acetylcholine receptor. Proc Natl Acad Sci U S A. 1992; 89(20):9949-9953. [PubMed: 1409725]

54. Cosgrove KP, et al. Sex differences in availability of beta $2 *$-nicotinic acetylcholine receptors in recently abstinent tobacco smokers. Arch Gen Psychiatry. 2012; 69(4):418-427. [PubMed: 22474108]

55. Logue PE, et al. Effects of ethanol and psychomotor tests on state anxiety: interaction with menstrual cycle in women. Percept Mot Skills. 1981; 52(2):643-648. [PubMed: 7255074]

56. Sutker PB, et al. Acute alcohol intoxication: sex comparisons on pharmacokinetic and mood measures. Alcohol Clin Exp Res. 1987; 11(6):507-512. [PubMed: 3324798]

57. Evans SM, Levin FR. Response to alcohol in women: role of the menstrual cycle and a family history of alcoholism. Drug Alcohol Depend. 2011; 114(1):18-30. [PubMed: 20888148]

58. Holdstock L, de Wit H. Effects of ethanol at four phases of the menstrual cycle. Psychopharmacology (Berl). 2000; 150(4):374-382. [PubMed: 10958078]

59. Stewart SH, et al. Relations between dietary restraint and patterns of alcohol use in young adult women. Psychol Addict Behav. 2000; 14(1):77-82. [PubMed: 10822749]

60. Khaylis A, Trockel M, Taylor CB. Binge drinking in women at risk for developing eating disorders. Int J Eat Disord. 2009; 42(5):409-414. [PubMed: 19115362]

61. Luce $\mathrm{KH}$, et al. Do restrained eaters restrict their caloric intake prior to drinking alcohol? Eat Behav. 2013; 14(3):361-365. [PubMed: 23910781]

62. DiMatteo J, Reed SC, Evans SM. Alcohol consumption as a function of dietary restraint and the menstrual cycle in moderate/heavy ("at-risk") female drinkers. Eat Behav. 2012; 13(3):285-288. [PubMed: 22664414]

63. Torres OV, et al. Female rats display enhanced rewarding effects of ethanol that are hormone dependent. Alcohol Clin Exp Res. 2014; 38(1):108-115. [PubMed: 23909760]

64. Roberts AJ, et al. Estrous cycle effects on operant responding for ethanol in female rats. Alcohol Clin Exp Res. 1998; 22(7):1564-1569. [PubMed: 9802543]

65. Kerstetter KA, et al. Sex and estrous cycle differences in cocaine-induced approach-avoidance conflict. Addict Biol. 2013; 18(2):222-229. [PubMed: 21309954]

66. Substance Abuse and Mental Health Services Administration. Non medical use of prescription pain relievers. 2004

67. Substance Abuse and Mental Health Services Administration. Results from the 2012 National Survey on Drug Use and Health: Summary of National Findings. Rockville, MD: 2013.

68. Andersson HI, et al. Chronic pain in a geographically defined general population: studies of differences in age, gender, social class, and pain localization. Clin J Pain. 1993; 9(3):174-182. [PubMed: 8219517]

69. Rustoen T, et al. Gender differences in chronic pain--findings from a population-based study of Norwegian adults. Pain Manag Nurs. 2004; 5(3):105-117. [PubMed: 15359222]

Curr Psychiatry Rep. Author manuscript; available in PMC 2015 November 01. 
70. Back SE, et al. Comparative profiles of men and women with opioid dependence: results from a national multisite effectiveness trial. Am J Drug Alcohol Abuse. 2011; 37(5):313-323. [PubMed: 21854273]

71. Sener EB, et al. Effects of menstrual cycle on postoperative analgesic requirements, agitation, incidence of nausea and vomiting after gynecological laparoscopy. Gynecol Obstet Invest. 2005; 59(1):49-53. [PubMed: 15467297]

72. Ribeiro-Dasilva MC, et al. Evaluation of menstrual cycle effects on morphine and pentazocine analgesia. Pain. 2011; 152(3):614-622. [PubMed: 21239109]

73. Cicero TJ, Aylward SC, Meyer ER. Gender differences in the intravenous self-administration of mu opiate agonists. Pharmacol Biochem Behav. 2003; 74(3):541-549. [PubMed: 12543217]

74. Stewart J, Woodside B, Shaham Y. Ovarian hormones do not affect the initiation and maintenance of intravenous self-administration of heroin in the female rat. Psychobiology. 1996; 24(2):154159.

75. Roth ME, Casimir AG, Carroll ME. Influence of estrogen in the acquisition of intravenously selfadministered heroin in female rats. Pharmacol Biochem Behav. 2002; 72(1-2):313-318. [PubMed: 11900802]

76. Griffin ML, et al. Alcohol use across the menstrual cycle among marihuana users. Alcohol. 1987; 4(6):457-462. [PubMed: 3435634]

77. Griffin ML, et al. Marihuana use across the menstrual cycle. Drug Alcohol Depend. 1986; 18(2): 213-224. [PubMed: 3780416]

78. Lex BW, et al. Effects of acute marijuana smoking on pulse rate and mood states in women. Psychopharmacology (Berl). 1984; 84(2):178-187. [PubMed: 6438677]

79. Fattore L, et al. Drug- and cue-induced reinstatement of cannabinoid-seeking behaviour in male and female rats: influence of ovarian hormones. Br J Pharmacol. 2010; 160(3):724-735. [PubMed: 20590575]

80. Winsauer PJ, et al. Long-term behavioral and pharmacodynamic effects of delta-9tetrahydrocannabinol in female rats depend on ovarian hormone status. Addict Biol. 2011; 16(1): 64-81. [PubMed: 21158010]

81. Vallee M, et al. Pregnenolone can protect the brain from cannabis intoxication. Science. 2014; 343(6166):94-98. [PubMed: 24385629]

82. Schneider M, Koch M. Chronic pubertal, but not adult chronic cannabinoid treatment impairs sensorimotor gating, recognition memory, and the performance in a progressive ratio task in adult rats. Neuropsychopharmacology. 2003; 28(10):1760-1769. [PubMed: 12888772]

83. Pope $\mathrm{H} \mathrm{Jr}$, et al. Early-onset cannabis use and cognitive deficits: what is the nature of the association? Drug Alcohol Depend. 2003; 69(3):303-310. [PubMed: 12633916] 